\title{
Disruption of the ech42 (Endochitinase-Encoding) Gene Affects Biocontrol Activity in Trichoderma harzianum P1
}

\author{
S. L. Woo, ${ }^{1}$ B. Donzelli, ${ }^{2}$ F. Scala, ${ }^{1}$ R. Mach, ${ }^{3}$ G. E. Harman, ${ }^{2}$ C. P. Kubicek, ${ }^{3}$ G. Del Sorbo, ${ }^{1}$ and \\ M. Lorito' \\ ${ }^{1}$ Dipartimento di Arboricoltura, Botanica e Patologia Vegetale, sezione di Patologia Vegetale, Università di \\ Napoli "Federico II" and CETELOBI, Portici, 80055, Napoli, Italy; ${ }^{2}$ Department of Horticultural Sciences, \\ NYSAES/Cornell University, Geneva, NY 14456, U.S.A.; ${ }^{3}$ Abteilung für Mikrobielle Biochemie, Institut für \\ Biochemische Technologie und Mikrobiologie, TU Wien, Getreidemarkt 9, A-1060 Wien, Austria \\ Accepted 20 January 1999.
}

\begin{abstract}
The biocontrol strain P1 of Trichoderma harzianum was genetically modified by targeted disruption of the singlecopy ech42 gene encoding for the secreted 42-kDa endochitinase (CHIT42). Stable mutants in which ech42 was interrupted, and unable to produce CHIT42, were obtained and characterized. These mutants lacked the ech42 transcript, the protein, and endochitinase activity in culture filtrates, and they were unable to clear a medium containing colloidal chitin. Other chitinolytic and glucanolytic enzymes expressed during mycoparasitism were not affected by the disruption of ech42. The disrupted mutant D11 grew and sporulated similarly to the wild type. In vitro antifungal activity of the $e c h 42$ disruptant culture filtrates against Botrytis cinerea and Rhizoctonia solani was reduced about $\mathbf{4 0 \%}$, compared with wild type; antifungal activity was fully restored by adding an equivalent amount of CHIT42 as secreted by P1. The mutant exhibited the same biocontrol effect against Pythium ultimum as strain $P 1$, but the antagonism against $B$. cinerea on bean leaves by the mutant was significantly reduced (33\% less biocontrol), compared with strain P1. Conversely, the endochitinase-deficient mutant performed better than the wild type (16\% improvement of survival) in biocontrol experiments in soil infested with the soilborne fungus $R$. solani. These results indicate that the antagonistic interaction between the $T$. harzianum strain and various fungal hosts is based on different mechanisms.
\end{abstract}

Trichoderma strains are the most extensively studied and applied fungal biocontrol agents (Chet 1987; Harman and Kubicek 1998; Whipps 1997; Kubicek and Harman 1998). The antifungal mechanisms by which these fungi function as biopesticides are not completely understood, and substantial differences in the mode of action and biocontrol activity have been found among Trichoderma strains during their interaction with various plant pathogens (Haran et al. 1996). Cell-

Corresponding author: M. Lorito; E-mail: lorito@unina.it

S. L. Woo and M. Lorito contributed equally to this work. wall-degrading enzymes, antibiotics, and other factors induced in the presence of the host fungus are thought to be directly involved (Lorito et al. 1996c; Lorito 1998; Schirmböck et al. 1994). Chitinolytic enzymes secreted by $T$. harzianum have received much attention because of their lytic and inhibitory activity toward many phytopathogenic fungi (de la Cruz et al. 1992; Lorito et al. 1993a, 1993b, 1994a, 1994b, 1996a, 1996c). Although several exo- and endochitinases have been purified and their genes cloned from different T. harzianum isolates (de la Cruz et al. 1992; Harman et al. 1993; Lorito et al. 1994a; Ulhoa and Peberdy 1991, 1992), the role of these enzymes in mycoparasitism, antagonism, or biocontrol has not yet been established.

The T. harzianum strain P1 is a well-studied isolate effective against foliar and post-harvest pathogens, such as Botrytis cinerea (Tronsmo 1991). Strain P1 secretes several chitinolytic enzymes including at least one $N$-acetyl- $\beta$-glucosaminidase (CHIT72), at least one chitin $1,4-\beta$-chitobiosidase (CHIT40), and a single 42-kDa endochitinase (CHIT42) (Harman et al. 1993; Lorito et al. 1994a; M. Lorito and S. L. Woo, unpublished). The CHIT42 endochitinase exhibits a strong lytic and antifungal activity in vitro and is the only enzyme produced by $\mathrm{P} 1$ that is capable of rapidly degrading a suspension of colloidal chitin (Harman et al. 1993). Strain P1 contains a single copy of the gene encoding for CHIT42, ech42 (previously named ThEn42; Hayes et al. 1994), which is expressed in the presence of chitin or fungal cell walls and in the early phases of the mycoparasitic interaction with $B$. cinerea and other fungi (Lorito et al. 1996b). Therefore, strain P1 appears suitable for gene disruption experiments to assess the role of CHIT42 in biocontrol. In this work we have disrupted the ech42 locus in $T$. harzianum P1 without affecting the $N$-acetyl- $\beta$-glucosaminidase (now considered to be $N$ acetylhexosaminidase) encoding gene nagl (Peterbauer et al. 1996) or other cell-wall-degrading enzyme activities induced during mycoparasitism. The resulting mutants, unable to produce CHIT42, have been characterized and tested for lytic, antifungal, and in vivo biocontrol activity against two different fungal pathogens. The disruption of ech 42 decreases biocontrol of B. cinerea but increases control of Rhizoctonia solani by $T$. harzianum $\mathrm{P} 1$. 


\section{RESULTS}

\section{Selection of mutants.}

Both biolistic and protoplast-mediated transformation of $T$. harzianum P1 with the plasmid pAN7-1-ech42 (Fig. 1) yielded about 500 to 800 transformants per microgram of DNA. Sixty stable homokaryotic hygromycin-resistant (HygR) transformants were obtained. Among these transformants, 29 grew and sporulated at about the same rate as the parental strain P1, 24 grew at $60 \%$, and 7 at $30 \%$ of the rate of the wild type. Twentysix transformants were unable to clear a chitin medium even after 2 weeks of cultivation (Fig. 2), 30 cleared chitin very slightly, and 4 cleared chitin as well as the wild type over this period. Fifteen transformants that grew and sporulated similarly to strain P1 but did not show any endochitinase activity in the plate assay were selected for nucleic acid analysis.

\section{Nucleic acid analysis.}

PCR (polymerase chain reaction) amplification with the primers $\mathrm{HpF}$ and $\mathrm{TrR}$ produced the expected 1.2-kb band, indicating that all of the HygR mutants, but not the wild-type strain, contained the hygromycin cassette from pAN7-1 (data not shown). Southern analysis with XbaI-digested DNA probed with the HindIII fragment of ech42 showed the expected bands for all the selected mutants $(1.7$ and $8.1 \mathrm{~kb})$ and the wild-type strain $(1.9 \mathrm{~kb})$, thus demonstrating that homolo-

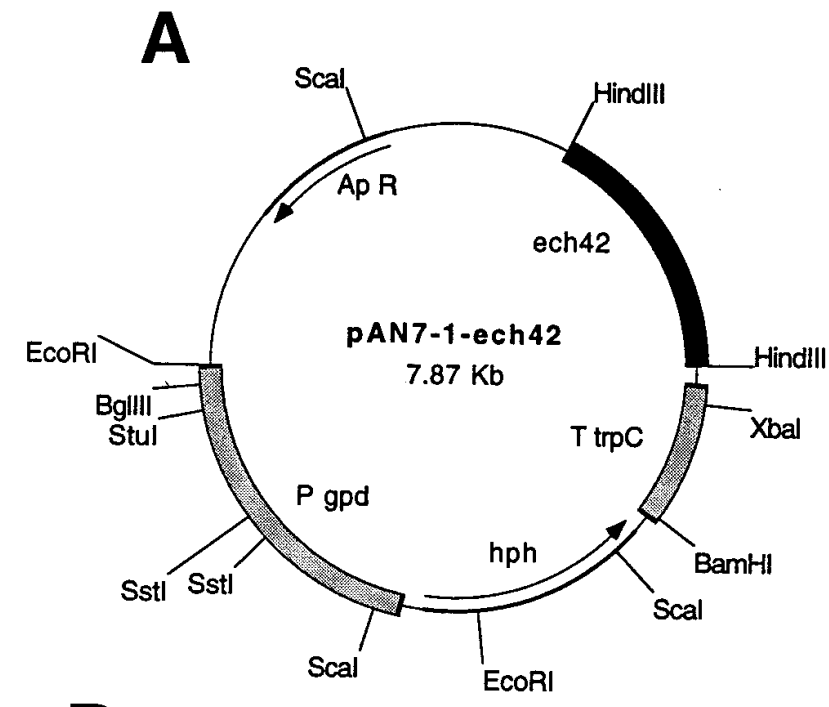

B

Strain P1 (wild type)

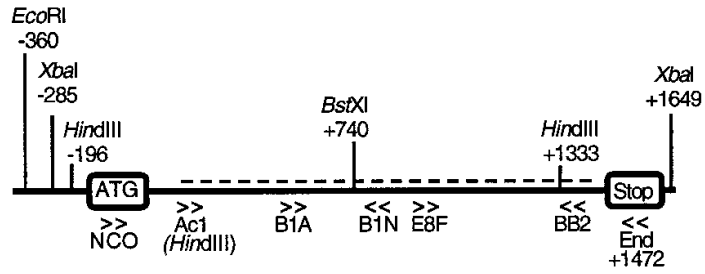

\section{Disrupted mutant}

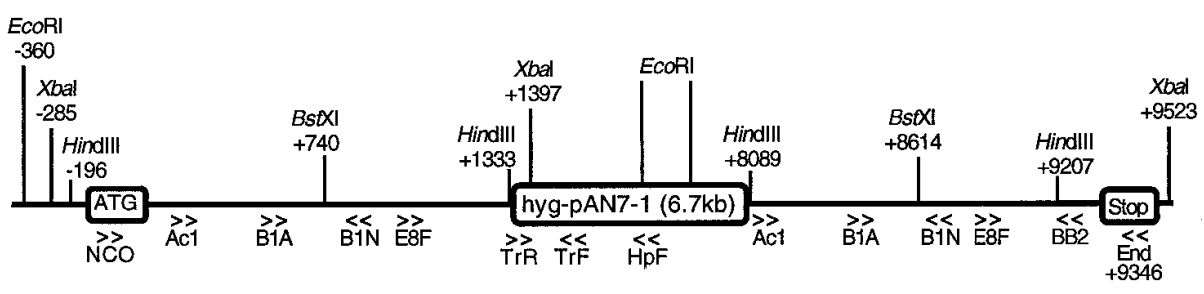

Fig. 1. Plasmid used for transformation, restriction, and PCR (polymerase chain reaction) maps of the ech42 locus in the Trichoderma harzianum strain P1 and disrupted mutants. A, Plasmid pAN7-1-ech42 was derived from pAN7-1 by inserting a 1,118-bp HindIII fragment of ech42 from T. harzianum; TtrpC $=$ terminator, Pgpd $=$ promoter, hph = hygromycin B phosphotransferase gene (Punt et al. 1987). B, Disruption of the ech42 gene; numbers indicate distance from the $5^{\prime}$ end of the coding sequence of ech42; boxes indicate the ATG, the stop codon TAG, and the vector pAN7-1, with the approximate sizes, containing the hygromycin resistance cassette (hyg-pAN7-1). Primers are indicated below the solid line at approximate positions, and symbols $\gg$ or $<<$ indicate primer directions. Primer sequences and positions are shown in Table 1. Primer Ac1 contains a new HindIII restriction site. Interrupted line on the wild-type map indicates the ech 42 fragment used for disruption. Distances and positions are only approximate. 
gous insertion occurred at the ech42 locus and the coding sequence was interrupted (Figs. 1B and 3A). Mutant strain D11 was arbitrarily selected for further analyses by PCR and DNA and RNA blotting. Southern analysis indicated that the ech42 locus was altered as indicated in Figure 1B; DNA cut with HindIII produced bands of $1.5 \mathrm{~kb}$ for P1 (Hayes et al. 1994) and of $1.5 \mathrm{~kb}$ as well as $1.1 \mathrm{~kb}$ for D11 (Figs. 1B and 3B). Further, EcoRI or EcoRV digests produced the expected banding pattern differences between the wild type and the mutant (Figs. 1B and 3B), which confirmed the integration of pAN7-1-ech42 at the homologous site. PCR analysis with various combinations of primers to amplify the $5^{\prime}$ end $(\mathrm{NCO}+$ $\mathrm{B} 1 \mathrm{~N})$, the $3^{\prime}$ end $(\mathrm{E} 8 \mathrm{~F}+\mathrm{End})$, or the entire sequence $(\mathrm{NCO}+$ End) of ech42 (Fig. 1B; Table 1) demonstrated the presence of two distal portions of the gene, and the lack of an intact copy of ech42 in the mutant D11 (Figs. 1B and 3C). To further confirm homologous insertion, PCR was performed with the

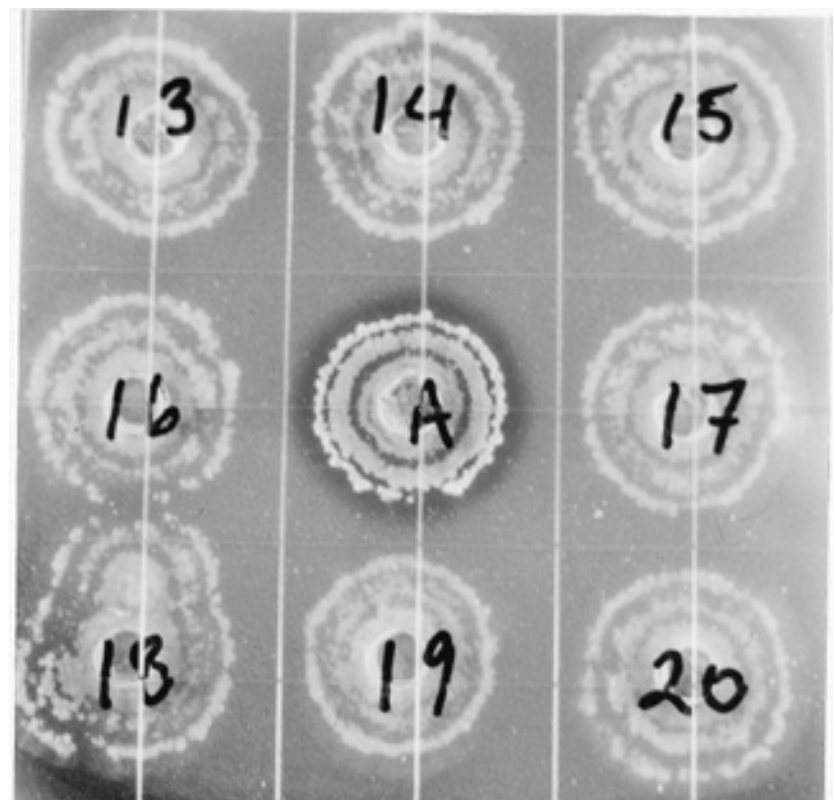

Fig. 2. Substrate clearing assay of the Trichoderma harzianum wild-type strain P1 (in the center indicated with 'A') and disrupted mutants (indicated with numbers) grown on a chitin-containing medium.

Fig. 3. Molecular characterization of Trichoderma harzianum $\mathrm{P} 1 \mathrm{mu}$ tants with a disrupted ech42 locus. A, Southern analysis of six representative homokaryotic progeny and the wild-type P1 strain; genomic DNA was digested with XbaI and probed with the HindIII fragment of ech42; size markers are indicated on the left in $\mathrm{kb}$. B, Southern analysis of wild-type strain P1 and mutant D11; DNA was digested with the indicated enzymes and probed with the entire ech42 coding region; size markers are indicated on the left in $\mathrm{kb}$. C, PCR (polymerase chain reaction) analysis of the ech42 locus with primers: Lanes 1 to $3, \mathrm{NCO}+$ End; lanes 4 to $6, \mathrm{E} 8 \mathrm{~F}+$ End; lanes 7 to $9, \mathrm{NCO}+\mathrm{B} 1 \mathrm{~N}$; lanes 10 and 11, $\mathrm{NCO}+\mathrm{TrF}$; lanes 12 and 13, E8F + HpF; lane 14, E8F + TrR; and lane $15, \mathrm{~B} 1 \mathrm{~N}+\mathrm{HpF} ; \mathrm{M}=\lambda$ HindIII markers 23.1, 9.4, 6.5, 4.3, 2.3, 2.0 $\mathrm{kb}$. The line above the lane numbers indicates DNA from wild-type strain $\mathrm{P} 1=\mathrm{P}$, mutant D11 = D, and cloned ech $42=\mathrm{e}$. D and E, Northern (RNA) analysis of total RNA obtained from wild-type P1, mutant D11 grown in ech42-inducing conditions on chitin or fungal cell walls (D11/i), or D11 grown in non-inducive conditions in the presence of glucose (D11/ni). DNA probes used are (D) the ech42 coding sequence, (E) the nagl coding sequence, and the 1.9-kb KpnI fragment of actl. primers $\mathrm{NCO}$ and $\mathrm{TrF}$, which anneal close to the ATG site of ech42 and in the hygromycin cassette of pAN7-1, respectively; this yielded no band in the wild type and the expected 1.9-kb band for the disrupted mutant (Figs. 1B and 3C; Table 1). Orientation of the insert in the mutant was determined with primers $\mathrm{E} 8 \mathrm{~F}+\mathrm{HpF}, \mathrm{E} 8 \mathrm{~F}+\mathrm{TrR}$, and $\mathrm{B} 1 \mathrm{~N}+\mathrm{HpF}$ (Figs. $1 \mathrm{~B}$ and 3C; Table 1). Northern (RNA) analysis of wild-type and D11 RNAs indicated the absence of ech 42 mRNA in the mutant when it was grown either in noninducive (i.e., on glucose) or highly inducive (i.e., on colloidal chitin or B. cinerea cell walls) conditions for ech42 expression (Fig. 3D; Garcia et al. 1994; Hayes et al. 1994; Lorito et al. 1996b). Southern blot
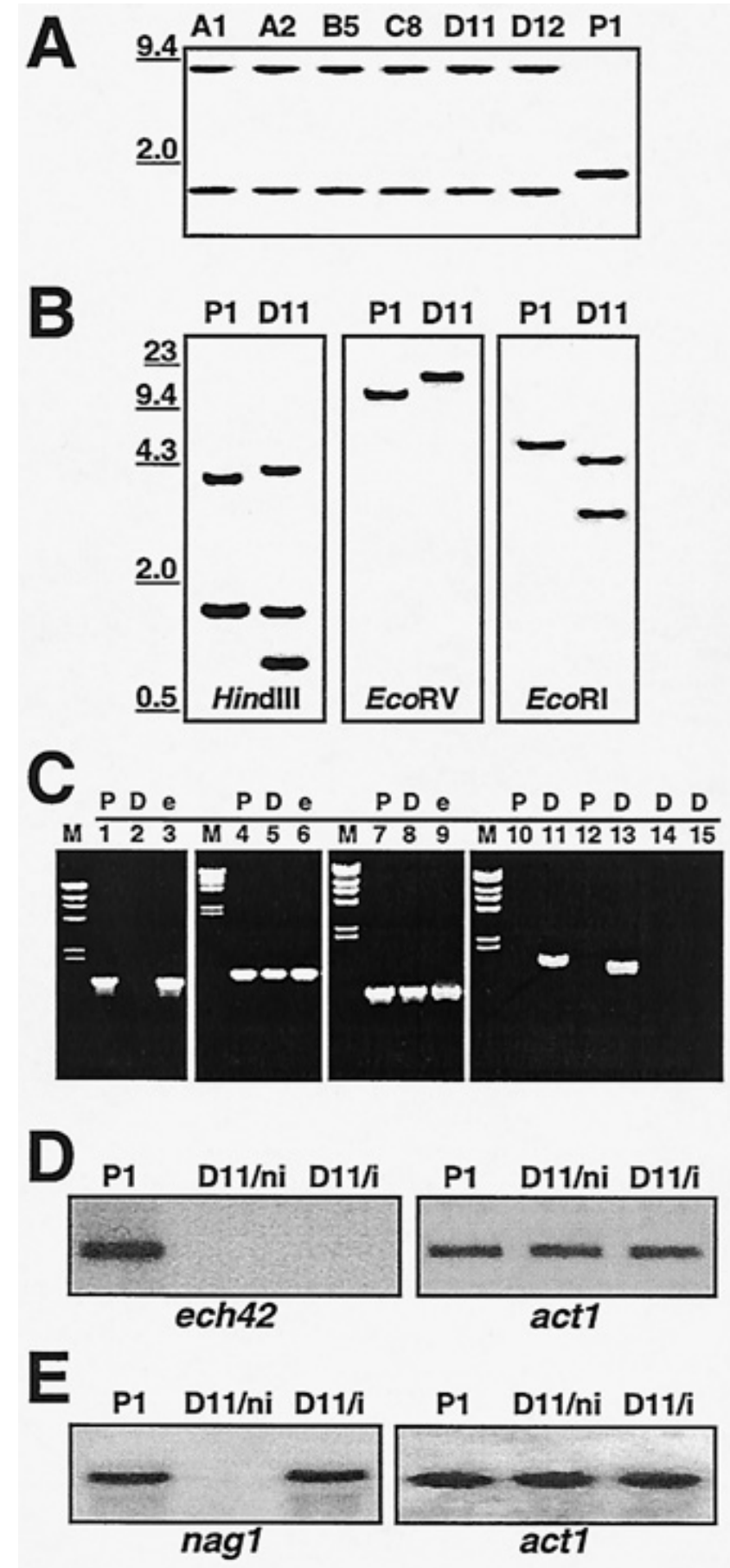
and PCR analyses performed on the $N$-acetyl- $\beta$-D-glucosaminidase-encoding gene nagl (Peterbauer et al. 1996), as well as RNA blot analysis of the corresponding mRNA, indicated that the integrity of the nagl locus and expression level of this gene were not affected by the disruption of ech42 (Fig. $3 \mathrm{E}$ and data not shown).

\section{Protein analysis.}

The presence of secreted endochitinase CHIT42 was tested in the culture filtrates of $\mathrm{P} 1$ and D11 grown in a minimal medium containing colloidal chitin or $B$. cinerea cell walls (de la Cruz et al. 1992; Harman et al. 1993). PAGE (polyacrylamide gel electrophoresis) of filtrates, followed by staining with either Coomassie blue or fluorescent substrates specific for chitinolytic activity, clearly indicated the presence of $\mathrm{N}$ acetyl- $\beta$-D-glucosaminidase activity and the absence of CHIT42 endochitinase in the D11 mutant filtrate, compared with the wild type (Fig. 4A, B). Enzyme-linked immunosorbent assays (ELISAs) performed with antibodies specific for CHIT42 (Harman et al. 1993) produced a strong reaction with P1 but no reaction with D11 culture filtrate, even when concentrated 100-fold (data not shown). The turbidity reduction test with colloidal chitin indicated that the high endochitinase activity found in the wild-type culture filtrate was absent in the mutant (Fig. 4C). The lack of endochitinase activity in the D11 filtrate lowered the amount of reducing sugars released from chitin (Fig. 5, chitinolytic), which depends on the activity of both endo- and exo-acting enzymes ( $N$-acetyl- $\beta$-Dglucosaminidases and chitin 1,4- $\beta$-chitobiosidases). Various chitinolytic and glucanolytic activities, such as $N$-acetyl- $\beta$-Dglucosaminidase (NAGase), chitin 1,4- $\beta$-chitobiosidase (chitobiosidase), exo-glucanase, and glucan 1,3- $\beta$-glucosidase ( $\beta$-1,3glucanase), were not found to be significantly different in culture filtrates of the mutant and the wild-type strains (Fig. 5).

\section{Biocontrol tests.}

In vitro assays of $B$. cinerea spore germination and hyphal elongation performed with the wild-type and strain D11 culture filtrates showed a significant reduction in antifungal activity for the endochitinase-deficient mutant (Fig. 6A-C). The

Table 1. Primers used in this study (see also Figure 1)

\begin{tabular}{|c|c|c|}
\hline Name & Sequence $\left(5^{\prime}-3^{\prime}\right)$ & Annealing position \\
\hline Ac1 & aagcttccagcctcagaacctgg $^{\mathrm{a}}$ & $\begin{array}{l}+215 \text { on } e c h 42 \text { with a new } \\
\text { HindIII site }\end{array}$ \\
\hline BB2 & caaggagtcagagccagtctt & +1367 on ech42 \\
\hline $\operatorname{TrF}$ & aggtaccgatttaatagctccatgtcaac & At the $5^{\prime}$ end of $\operatorname{trp} C$ in pAN7-1 \\
\hline B1N & gtggtagcccgaagcgtatt & +813 on ech42 \\
\hline B1A & cttctgcagcaagcaccgat & +610 on ech42 \\
\hline $\mathrm{HpF}$ & catggatgcgatcgctgcg & $\begin{array}{l}\text { About } 300 \text { bp from the } 5^{\prime} \text { end } \\
\text { of } h p h \text { in pAN7-1 }\end{array}$ \\
\hline $\operatorname{TrR}$ & aggtaccgtctagaaagaaggattacctc & At the $3^{\prime}$ end of $\operatorname{trp} C$ in pAN7-1 \\
\hline $\mathrm{E} 8 \mathrm{~F}$ & tcaacctcatggectacgact & +898 on ech42 \\
\hline End & ggggggatcctctagttgagaccgcttc & $\begin{array}{l}+1472 \text { on the stop codon at the } \\
3^{\prime} \text { end of ech } 42\end{array}$ \\
\hline $\mathrm{NCO}$ & $\begin{array}{l}\text { gtcctaccatggtgggettcctcggaaa } \\
\text { aaatc }\end{array}$ & +5 at the $5^{\prime}$ end of $e c h 42$ \\
\hline $95 \mathrm{~F}$ & cgectcggtcgtccatcat & +95 close to the $5^{\prime}$ end of nag 1 \\
\hline $535 \mathrm{~F}$ & ggataccgcgaccaccttc & +535 on nag 1 \\
\hline 1480R & aatgaccttgtagccagactcg & +1480 on nag 1 \\
\hline 1989R & cttatgcgaacaaggtgcaagccgta & +1989 close to the $3^{\prime}$ of $n a g 1$ \\
\hline
\end{tabular}

a A guanine (underlined bold) was added in the sequence of Ac1 to generate a HindIII restriction site. inhibitory effect of the culture filtrate of the mutant strain was fully recovered by adding 5 to $10 \mu \mathrm{g}$ of purified endochitinase (CHIT42) per $\mathrm{ml}$ from strain P1 (the enzyme concentration secreted by P1 during growth on cell walls is 5 to $10 \mu \mathrm{g} / \mathrm{ml}$; Harman et al. 1993; M. Lorito and S. L. Woo, unpublished; Fig. 6D,E). The in vitro inhibition of $R$. solani mycelial growth obtained with the wild-type filtrate was also reduced
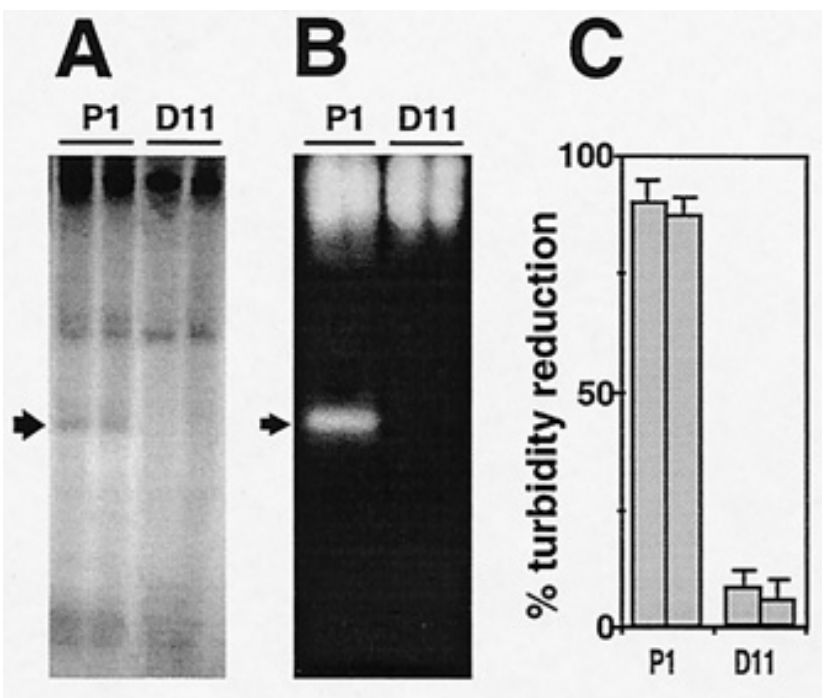

Fig. 4. Presence of CHIT42 (indicated by arrow) in the culture filtrates of the Trichoderma harzianum wild-type strain P1 and the disrupted mutant D11. A, PAGE (polyacrylamide gel electrophoresis) gel stained with Coomassie blue. B, PAGE gel overlaid with a solution of methylumbelliferyl-bound substrates for endochitinase and $N$-acetyl- $\beta$-Dglucosaminidase activities and photographed under UV light (Tronsmo and Harman 1993; incubation time after overlay $=15 \mathrm{~min}$ ); $N$-acetyl- $\beta$ D-glucosaminidase activity is localized at the top of the running gel. C, Endochitinase activity in the filtrates was measured as reduction in turbidity of a suspension of colloidal chitin.

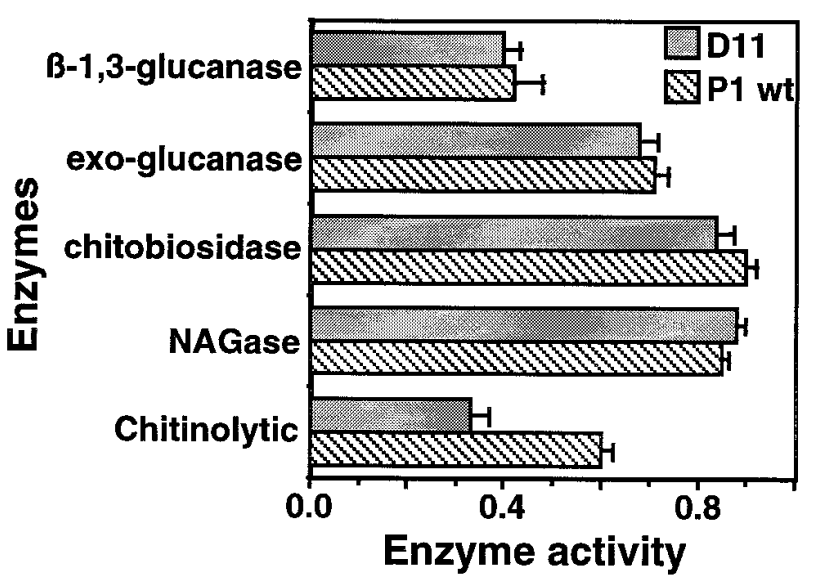

Fig. 5. Various enzyme activities in the culture filtrates of the Trichoderma harzianum wild-type strain P1 and disrupted mutant D11. Enzyme activities are indicated as absorbance at 405 (exo-glucanase, chitobiosidase, NAGase; assay incubation $30 \mathrm{~min}$ at $\left.45^{\circ} \mathrm{C}\right)$ or $510 \mathrm{~nm}(\beta-$ 1,3-glucanase and chitinolytic) (assay incubation 6 to $24 \mathrm{~h}$ at 30 to $40^{\circ} \mathrm{C}$ ) of the test solution. Chitobiosidase activity was tested with the dimeric substrate $p$-nitrophenyl $\beta$-D- $N, N^{\prime}$-diacetylchitobiose and is a combination of both NAGase and chitobiosidase activities. Chitinolytic $=$ total chitinolytic activity on chitin measured by the reducing sugars assay. Bar indicates standard deviation. 
by about $40 \%$ when filtrate from mutant D11 instead of P1 was applied (data not shown). When P1 and D11 were tested in plate confrontation assays against B. cinerea or $R$. solani, no obvious differences were observed in their ability to overgrow the two host pathogens.

Both the wild-type and the mutant strains exhibited similarly high levels of biocontrol activity $(P=0.336$ for percent survival and $P=0.383$ for plant height) against Pythium ultimum, which does not contain chitin, in soil tests. This indicated that the fitness of the mutant was not affected by the disruption of ech42 and the lack of endochitinase production (Table 2). In vivo tests performed against $B$. cinerea by leaf inoculations of bean plants also revealed a high biocontrol ac- tivity by strain P1 (Fig. 7; Table 3). However, a significantly lower level of biocontrol ability $(P<0.01)$, corresponding to more symptoms of chlorosis and/or necrosis, was noted when the mutant D11 was tested (Fig. 7; Table 3). In vivo biocontrol tests against $R$. solani demonstrated that strain $\mathrm{P} 1$ had a more limited effect on disease development of this soilborne fungus; a significantly higher biocontrol activity was noted when the endochitinase-deficient mutant was tested against this pathogen (Fig. 8; Table 4). Compared with the wild-type strain, D11 increased survival $(P<0.05)$ and enhanced plant growth $(P$ $=0.006$ ) in soil heavily infested with $R$. solani (Fig. 8; Table 4). Generally, plants treated with the endochitinase-deficient mutant D11 appeared more healthy and grew more rapidly than those
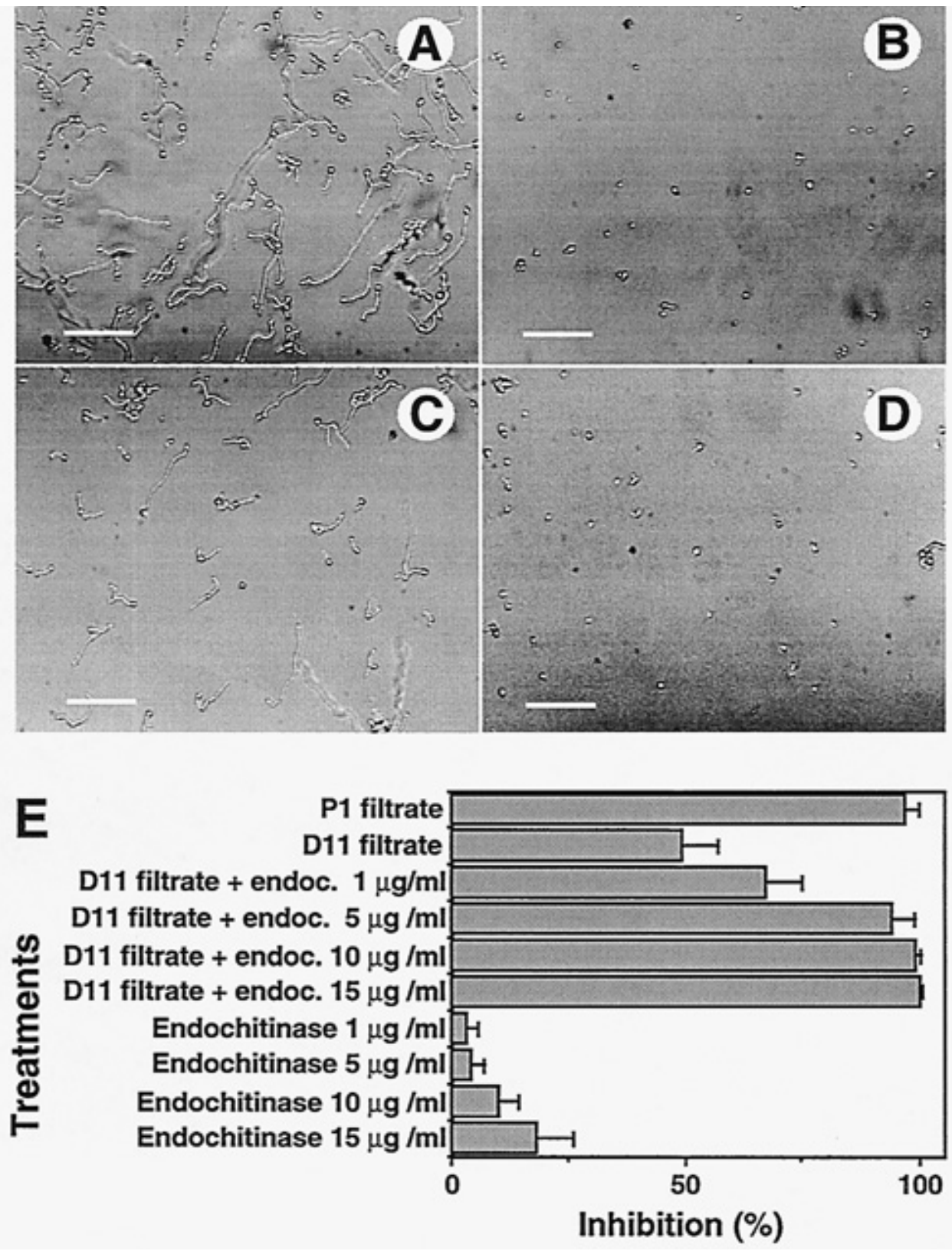

Fig. 6. In vitro inhibition of Botrytis cinerea by culture filtrates of the Trichoderma harzianum wild-type strain P1 or the disrupted mutant D11. A, Water control; B, P1 filtrate; C, D11 filtrate; D, D11 filtrate plus $10 \mu \mathrm{g}$ of purified CHIT42 per ml; bar $=24 \mu \mathrm{m}$. E, Inhibition of $B$. cinerea germ tube elongation by the filtrates and/or CHIT42 at various concentrations. P1 and D11 filtrates contained the same total protein concentration. Bars indicate standard deviations. 
treated with P1 (Fig. 8). Macro- and microscopic examination of the attached seed coats after plant emergence indicated an apparent increase of Trichoderma harzianum growth on the surface with the D11 treatments (data not shown), suggesting that the lack of CHIT42 may have stimulated colonization of the spermosphere and the rhizosphere.

\section{DISCUSSION}

Recent applications of Trichoderma spp.-based biofungicides/ biofertilizers in commercial agriculture have stimulated many studies of the biocontrol and mycoparasitic mechanisms of these fungi (Harman and Hayes 1996; Harman and Kubicek 1998; Kubicek and Harman 1998). Genes and compounds involved in the antifungal activity of Trichoderma spp. have been isolated, and experiments with mutants having specific gene functions disrupted or enhanced can now be performed. In particular, cell-

Table 2. Evaluation of biocontrol effect of wild-type and mutant Trichoderma harzianum, applied as seed treatment, on the emergence and growth of beans 11 to 14 days after seeding in Pythium ultimuminfested soil

\begin{tabular}{lcc}
\hline Seed treatment & ${\text { Survival }(\boldsymbol{\%})^{\mathbf{a}}}$ & ${\text { Plant height }(\mathbf{c m})^{\mathbf{b}}}^{\mathbf{b}}$ \\
\hline P1 + Pelgel & 85.6 & 19.3 \\
D11 + Pelgel & 79.2 & 19.5 \\
Pelgel alone & 33.3 & NA $^{\mathrm{c}}$ \\
Water & 24.6 & NA \\
\hline
\end{tabular}

a Number of emergent surviving plants during evaluation period. Analysis of variance of arcsine transformed percent values: P1 vs D11 not significantly different $(P=0.336) ; \mathrm{P} 1 / \mathrm{D} 11$ vs $P$ elgel/water alone $P<$ 0.001 .

${ }^{\mathrm{b}}$ Unpaired $t$ test of plant height $\mathrm{P} 1 \mathrm{vs} \mathrm{D} 11$ not significantly different $(P$ $=0.383$ ).

${ }^{c}$ Not applicable, plants in poor condition. wall-degrading enzymes of a few Trichoderma spp. and the genes that encode them have received attention for their potential in agricultural or industrial applications (Lorito 1998; Lorito et al. 1998). The contribution of chitinolytic enzymes to the antagonism of Trichoderma spp. against various host pathogens is still debated (Belanger et al. 1995; Lorito 1998). It has been suggested that antagonistic Trichoderma strains produce chitinolytic enzymes only to colonize saprophytically hosts that have been previously killed by antibiotics (Belanger et al. 1995), and a correlation between in vitro chitinolytic activity of various Trichoderma strains and biocontrol efficacy in vivo has not yet been demonstrated. In addition, mechanisms other than parasitism have been suggested for some biocontrol strains (Caron 1993; Howell 1987; Lumsden and Lewis 1989; Prokkola 1992). However, the following evidence supports the involvement of chitinolytic enzymes in mycoparasitism and biocontrol: (i) in vitro expression of ech 42 occurs before the contact with host (Galhaup et al. 1998) or in the first few hours of the mycoparasitic interaction (Carsolio et al. 1994; Inbar and Chet 1995; Lorito et al. 1996b); (ii) purified chitinolytic enzymes are inhibitory to a variety of fungi (Di Pietro et al. 1993; Lorito et al. 1993b, 1994a); (iii) chitinase production in mycoparasitic but not in nonmycoparasitic strains of $T$. harzianum is highly induced by autoclaved host mycelia (Garcia et al. 1994); (iv) increased chitinolytic activity in T. harzianum and expression of a $T$. harzianum chitinase-encoding gene in Escherichia coli augment biocontrol ability (Chet et al. 1993; Limón et al. 1996); and (v) chitinolytic enzymes and antibiotics such as gliotoxin and trichorzianines may be concurrently produced during antagonism and act synergistically against the fungal host (Di Pietro et al. 1993; Lorito et al. 1996a; Schirmböck et al. 1994).

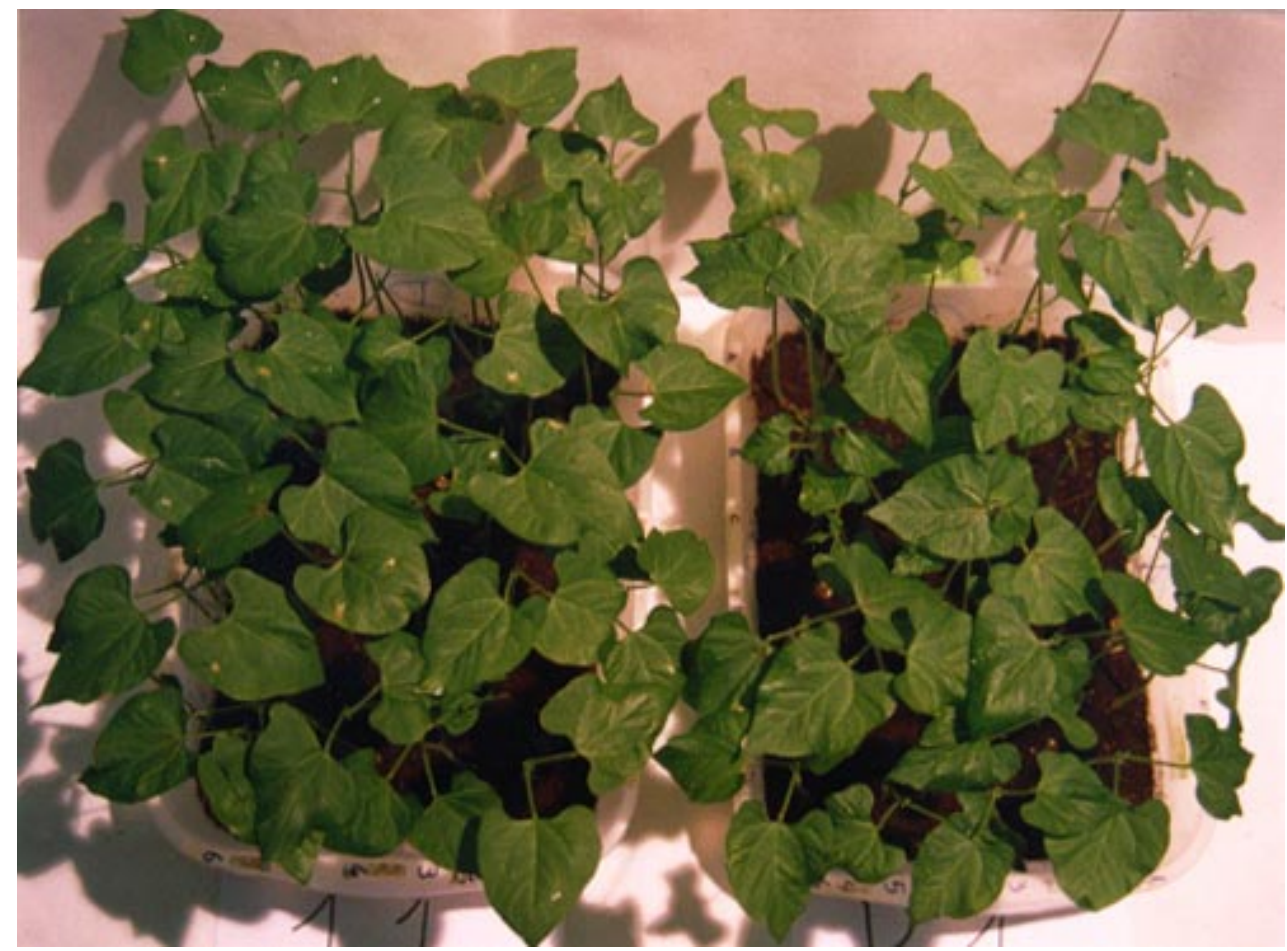

Fig. 7. Evaluation of biocontrol effect of wild-type and mutant Trichoderma strains on the development of Botrytis cinerea disease symptoms on bean leaves. Observation of developing disease reactions on bean leaves inoculated with spores of B. cinerea and mutant D11 (left) or B. cinerea and wildtype strain P1 (right). 
The literature on chitinolytic enzymes strongly suggests that major differences in the enzyme composition may occur between different biocontrol strains of Trichoderma (for a review see Lorito 1998). The endochitinase CHIT42 appears to be commonly present, while the $\beta-N$-acetylhexosaminidase ( $N$-acetyl- $\beta$-D-glucosaminidase) CHIT102 and the endochitinases CHIT52 and CHIT33 have been found in some $T$. harzianum strains but not in $\mathrm{P} 1$, and the chitobiosidase CHIT40 has only been detected in P1 (de la Cruz et al. 1992; Haran et al. 1994; Harman et al. 1993; Lorito 1998). Therefore, the role of some chitinolytic enzymes and the effect of the disruption of the encoding genes may differ depending on the strain considered. In this work we used P1, a biocontrol strain found to be more effective against foliar and postharvest pathogens than against soilborne pathogens. This strain apparently secretes CHIT42 as the only endochitinase and has never been reported to produce nonvolatile antibiotics (Harman et al. 1993; M. Lorito and S. L. Woo, unpublished). The disruption of ech42 in T. harzianum P1 significantly reduced the protective effect of this strain, demonstrating a key role of the endochitinase CHIT42 in the inhibition of B. cinerea in vivo. It should be noted that the reduction of biocontrol activity was not complete, indicating that other factors contribute to the control of $B$. cinerea by $\mathrm{P} 1$.

The filtrate of the endochitinase-deficient mutant still inhibited hyphal elongation of $B$. cinerea in vitro, probably due to the fact that strain P1 secretes several antifungal enzymes, including fungicidal endo- and exochitinases and glucanases (Lorito et al. 1993b, 1994a). The antifungal activity of the fil-

Table 4. Biocontrol effect of wild-type and mutant Trichoderma harzianum, applied as seed treatment, on the emergence and growth of beans 16 days after seeding in soil infested with Rhizoctonia solani

\begin{tabular}{lcc}
\hline Seed treatment & Survival $(\%)^{\mathbf{a}}$ & ${\text { Height }(\mathbf{c m})^{\mathbf{b}}}^{\text {P1 + Pelgel }}$ \\
D11 + Pelgel & 71.0 & 11.8 \\
Pelgel alone & 86.5 & 14.5 \\
Water & 24.5 & $\mathrm{NA}^{\mathrm{c}}$ \\
\hline
\end{tabular}

a Number of emergent plants during evaluation period. Analysis of variance of arcsine transformed percent values: P1 + Pelgel vs D11+ Pelgel, significantly different $(P<0.05)$; P1 + Pelgel/D11 + Pelgel vs Pelgel/water alone, $P<0.001$.

${ }^{\mathrm{b}}$ Unpaired $t$ test of plant height $\mathrm{P} 1+$ Pelgel vs D11 + Pelgel significantly different $(P=0.006)$.

${ }^{\mathrm{c}}$ Not applicable, plants in poor condition.

Table 3. Biocontrol effect of wild-type and mutant Trichoderma strains on the development of Botrytis cinerea disease symptoms ${ }^{\text {a }}$ on bean leaves

\begin{tabular}{|c|c|c|c|c|c|c|c|c|c|}
\hline \multirow[b]{2}{*}{ Treatment (spore inoculation) } & \multirow{2}{*}{$\begin{array}{l}\text { Any disease } \\
\text { reaction }^{b, c}\end{array}$} & \multirow{2}{*}{$\begin{array}{c}\text { Total } \\
\text { chlorosis }\end{array}$} & \multicolumn{3}{|c|}{ Severity of chlorosis } & \multirow{2}{*}{$\begin{array}{c}\text { Total } \\
\text { necrosis }\end{array}$} & \multicolumn{3}{|c|}{ Severity of necrosis } \\
\hline & & & Slight & Medium & Severe & & Slight & Medium & Severe \\
\hline $\mathrm{P} 1+$ Botrytis & 26.9 & 28.8 & 27.3 & 1.5 & 0 & 12.1 & 4.5 & 7.6 & 0 \\
\hline D11 + Botrytis & 47.6 & 47.1 & 33.5 & 12.9 & 0.7 & 32.1 & 14.0 & 7.0 & 11.1 \\
\hline Botrytis alone & 62.9 & 63.7 & 36.7 & 19.8 & 7.2 & 36 & 13.2 & 11.0 & 11.8 \\
\hline Trichoderma P1/D11 alone & 5.8 & 6.7 & 6.7 & 0 & 0 & 4.2 & 4.2 & 0 & 0 \\
\hline
\end{tabular}

$\bar{a}$ Percentage of total inoculation points showing any disease reaction, chlorosis, necrosis, and different severity of chlorosis or necrosis 16 to 23 days after inoculation.

b Total reactions observed (chlorosis, necrosis, or chlorosis + necrosis).

c Analysis of variance of arcsine transformed percent disease reaction values: $\mathrm{P} 1+$ Botrytis vs D11 + Botrytis, $P<0.01$; P1 + Botrytis vs Botrytis alone, $P<0.001$; D11 + Botrytis vs Botrytis alone, $P<0.05 ; \mathrm{P} 1+$ Botrytis/D11+ Botrytis/Botrytis alone vs Trichoderma P1/D11 alone, $P<0.001$, Trichoderma P1/D11 vs water, NS.

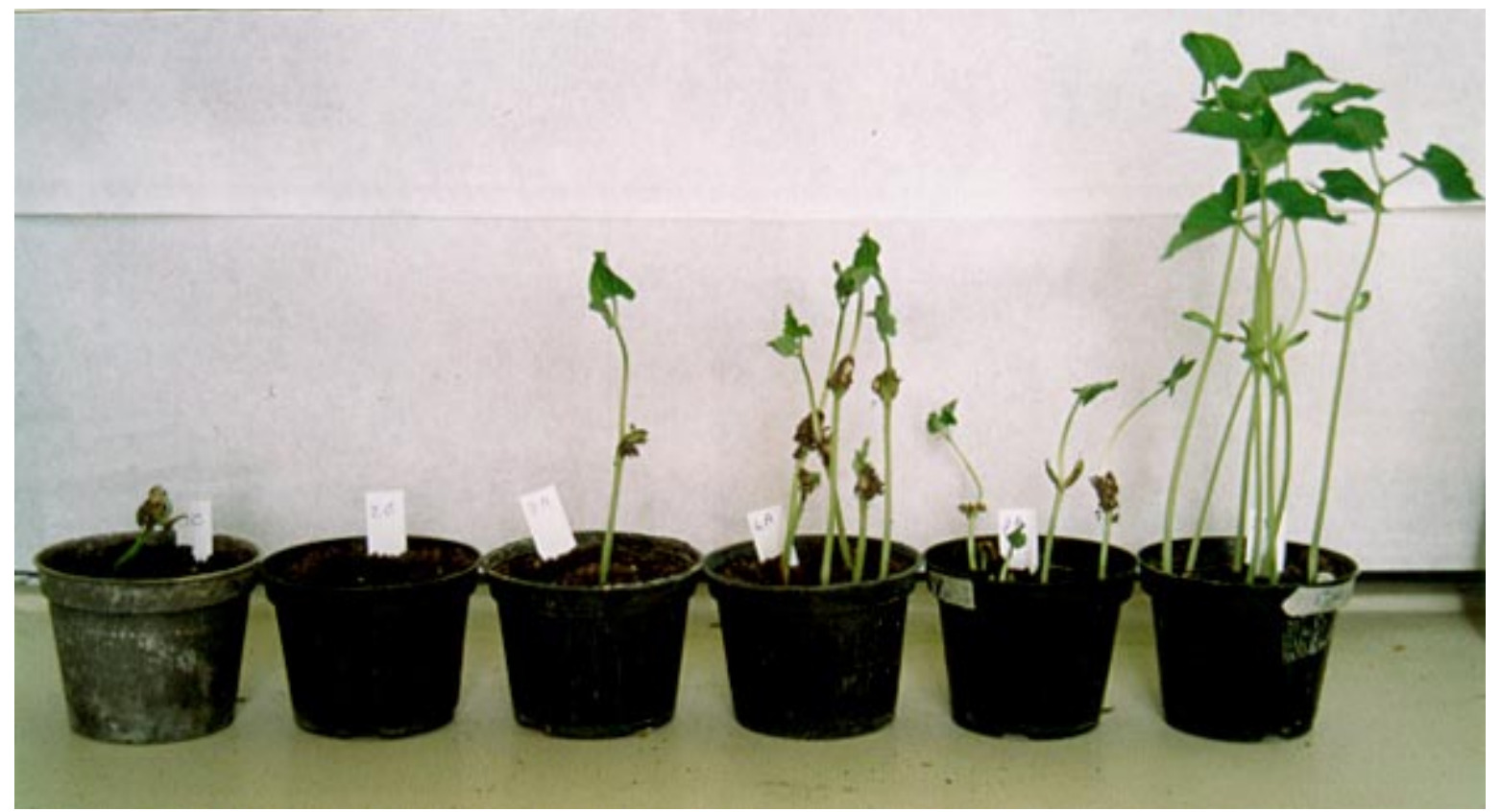

Fig. 8. Evaluation of biocontrol effect of wild-type and mutant Trichoderma harzianum strains on bean seeds in Rhizoctonia solani-infested soil. Differences in plant emergence and growth of bean seeds treated with (from left to right) Pelgel, water, T. harzianum P14, mutant D11, wild-type P1, and control in the absence of $R$. solani. T. harzianum $\mathrm{P} 14$ is a weak biocontrol agent against $R$. solani and was used as an additional control. Each pot contained 7 bean seeds. 
trate could be restored to the level of the wild-type strain by adding sublethal doses (i.e., $5 \mu \mathrm{g} / \mathrm{ml}$ ) of purified CHIT42, and the inhibitory effect of the combination of D11 filtrate plus CHIT42 was clearly synergistic (Fig. 6; Lorito et al. 1996c). This is in accordance with our previous findings that different cell-wall-degrading enzymes produced by $T$. harzianum can be combined at low doses, also with antibiotics (trichorzianines or gliotoxin), to form strong synergistic mixtures (Lorito et al. 1994a, 1996a, 1996c; Schirmböck et al. 1994). All these results clearly indicate that the antifungal and biocontrol activity of Trichoderma spp. is supported by the production of powerful mixtures of degradative and toxic compounds.

The disruption of ech42 did not affect the formation of other chitinolytic or glucanolytic enzyme activities, such as the chitobiosidase CHIT40 or the $\beta-N$-acetylhexosaminidase ( $N$-acetyl- $\beta$-D-glucosaminidase) CHIT72 (also known as CHIT73; Haran et al. 1994; Lorito 1998), which are also thought to be involved in antagonism and biocontrol. Furthermore, Peterbauer et al. (1996) and Limón et al. (1995) observed that the expressions of ech42, nag1, and chit33 in T. harzianum have different patterns of induction. This indicates that the various components of the chitinolytic system of $T$. harzianum have independent mechanisms of gene regulation.

In contrast to the results obtained with $B$. cinerea, the endochitinase-deficient mutant performed better as a biocontrol agent than the wild type when applied as a seed coating on bean against the soilborne pathogen $R$. solani. Compared with $\mathrm{P} 1$, the treatment with the mutant improved both the emergence and the growth of the surviving plants (Fig. 8; Table 4). The differential effect of the ech42 disruption on the biocontrol of $B$. cinerea and $R$. solani strongly suggests that $T$. harzianum interacts in different ways against various pathogens. Depending on the fungal host and/or the plant involved, a single strain may employ distinct mechanisms of biocontrol and each chitinolytic enzyme may play substantially different roles in the mycoparasitic process. Haran et al. (1996) also reported a host influence on the expression of several chitinolytic enzymes when a $T$. harzianum strain was confronted with $R$. solani or Sclerotium rolfsii.

$R$. solani cell walls are strong inducers of ech42 expression (Garcia et al. 1994), both strains P1 and D11 are excellent parasites of this pathogen in vitro, and the antifungal activity of culture filtrates against $R$. solani is reduced for D11 in the absence of CHIT42. However, the ech42-deficient mutant exhibited improved biocontrol ability against this pathogen, compared with the wild type. The reasons for this finding are not known. Apparently, the altered Trichoderma strain grew more abundantly than P1 on the bean seeds, which may have helped in excluding $R$. solani from the spermosphere and rhizosphere. Melo et al. (1997) have recently shown that cellulasedeficient mutants of $T$. harzianum have an enhanced rhizosphere competence on bean, suggesting a relationship between rhizosphere competence and production of some extracellular enzymes. Several possibilities for differential antagonism of such enzymes exist: (i) the mutant D11 utilizes chitinolytic enzymes other than CHIT42 against $R$. solani (i.e., many $T$. harzianum chitinolytic enzymes have strong lytic activity on $R$. solani; Lorito et al. 1994a), while the energy saved from the lack of CHIT42 synthesis could support faster seed colonization or stronger antagonistic activity in the absence of a complex antagonist microflora in pre-sterilized soil; (ii) the absence of a key enzyme for mycoparasitism may stimulate the fungus to activate other mechanisms of biocontrol that are more effective in disease control; (iii) the absence of CHIT42 may alter the plant-Trichoderma spp. interaction by eliciting the defense reaction of the plant against $R$. solani (Benhamou et al. 1997); or (iv) CHIT42 may also have a physiological role (i.e., autolysis) and the lack of it may alter the strain's behavior in the soil under the conditions used in the assay. Some of these hypotheses may be verified by preparing and testing mutants with other chitinase-encoding genes disrupted.

The results obtained with $B$. cinerea and $R$. solani confirm the importance of the role of the endochitinase CHIT42 in the biocontrol mechanism of $T$. harzianum and the usefulness of disrupted mutants in improving our understanding of this fungus. Genetically modified Trichoderma strains that constitutively over-express chitinase genes may be superior biocontrol agents, but the deletion of some of these genes may also be useful to enhance selective plant protection.

\section{MATERIALS AND METHODS}

\section{Strains and culture conditions.}

The T. harzianum strain P1 (American Type Culture Collection 74058) used in this study was isolated from wood chips and selected for fungicide resistance (Tronsmo 1991). P1 is a biocontrol strain effective mainly against airborne pathogens, including Botrytis cinerea (Tronsmo 1991). Strain P1 and mutant derivatives were maintained at $25^{\circ} \mathrm{C}$ on potato dextrose agar (PDA) without or with $150 \mu$ g of hygromycin B per ml (Hyg B; Calbiochem, La Jolla, CA), respectively, and conserved as a spore suspension in $10 \%$ glycerol at $-80^{\circ} \mathrm{C}$. To obtain culture filtrates under inducing conditions for ech42 expression, fungi were grown on potato dextrose broth (PDB) at $25^{\circ} \mathrm{C}, 160 \mathrm{rpm}$ (orbital incubator model INR-250; Gallenkamp, Loughborough, Leicestershire, U.K.), for 3 days. Biomass was harvested, rinsed twice with sterile, distilled water, transferred to a salt medium (SM) (Harman et al. 1993) containing 0.1\% (wt/vol) sucrose and $4.2 \%(\mathrm{wt} / \mathrm{vol})$ chitin or $0.1 \%(\mathrm{wt} / \mathrm{vol})$ B. cinerea cell walls (Schirmböck et al. 1994) as carbon sources, and allowed to grow for 4 to 8 days (Harman et al. 1993; Lorito et al. 1994a). Non-inducing conditions consisted of SM containing 3\% (wt/ vol) glucose instead of chitin or cell walls (Garcia et al. 1994). Cultures were harvested aseptically and passed through a Buchner funnel lined with a double layer of Miracloth (Calbiochem), and the filtrates were stored at $4^{\circ} \mathrm{C}$. The harvested mycelia were placed in liquid nitrogen, lyophilized, and stored at $-20^{\circ} \mathrm{C}$. The $B$. cinerea strain 319 , isolated from tobacco, Pythium ultimum isolate $\mathrm{P} 4$ from infected field soil, and the $R$. solani strain 1556 , isolated from tomato, were used in biological control tests. $B$. cinerea was grown on malt extract agar at $25^{\circ} \mathrm{C}$ until sporulation and a spore suspension was stored in $10 \%$ glycerol at $80^{\circ}$ C. P. ultimum-infected soil was stored at $20^{\circ} \mathrm{C}$, and cultures of both $P$. ultimum and $R$. solani were stored on cornmeal agar, PDA, or wheat seed at $4^{\circ} \mathrm{C}$. $R$. solani was grown in PDB on a rotary shaker at $150 \mathrm{rpm}$ (orbital incubator model INR-250; Gallenkamp, Loughborough, Leicestershire, U.K.) and $25^{\circ} \mathrm{C}$ with light for 5 days and mycelia were used as a soil inoculum.

\section{Plasmids and transformation.}

A 1,152-bp fragment of ech42 was amplified by PCR from strain P1 genomic DNA with the primers Ac1 (+215) and BB2 
(+1367) (Table 1; Fig. 1B; Hayes et al. 1994; Garcia et al. 1994). Primer Ac1 contained an additional base to generate a HindIII restriction site while primer BB2 is located downstream of the only HindIII restriction site $(+1333)$ of the ech42 coding sequence. The PCR fragment was eluted from the gel (QIAquick Gel Extraction Kit; Qiagen, Hilden, Germany) and cloned in the plasmid pGEM-T (Promega, Madison, WI). Plasmid DNA from bacterial colonies containing the resulting pGEM-T-ech42 construct was digested with HindIII and the resulting ech42-containing fragment $(1,118 \mathrm{bp})$ was cloned into the HindIII site of the vector pAN7-1 $(6,756 \mathrm{bp})$ alongside the $\operatorname{trpC}$ gene of the hygromycin B resistance cassette (Punt et al. 1987). The orientation of the insert was determined by PCR with the primers $\operatorname{TrF}$, which anneals at the $5^{\prime}$ end of $\operatorname{trp} C$ (Fig. 1A) at about $570 \mathrm{bp}$ from the insert and amplifies toward the HindIII site, and ech42-specific primers directed toward the $5^{\prime}$ end $(\mathrm{B} 1 \mathrm{~N}$ at +813$)$ or the $3^{\prime}$ end $(\mathrm{Ac} 1$ at +215 or B1A at + 610) of the gene (Fig. 1; Table 1). Strain P1 was transformed with the resulting vector pAN7-1-ech42 (7,874 bp), which was undigested or linearized with BstXI (+740; Fig. 1A). Protoplast and biolistic transformations of T. harzianum were performed as previously described (Lorito et al. 1993c).

\section{Selection of transformants.}

Selection of transformants was conducted on PDA containing $300 \mu \mathrm{g}$ of Hyg B per ml (unless otherwise indicated) at $25^{\circ} \mathrm{C}$, and putative transformants were selected, transferred to fresh selective medium, and allowed to sporulate. To obtain homokaryons, single spores were isolated from each selected heterokaryotic transformant and transferred to fresh selective medium. This monoconidial transfer was conducted twice. Finally, 60 homokaryotic progeny were selected and further subcultured to determine the occurrence of abortive transformants. The stability of these transformants was also tested by two additional, single-spore transfers on nonselective and then again on selective medium, and by several mycelial transfers on selective plates (Lorito et al. 1993c).

The following criteria were applied for further selection of the transformants: (i) presence of the hygromycin resistance cassette in the fungal genome, which was tested by PCR amplification with primers $\mathrm{HpF}$ and TrR (Fig. 1; Table 1); (ii) presence of the expected bands after Southern analysis of the fungal DNA digested with XbaI (-285 and +1649) and probed with the HindIII fragment of ech42 cloned in pGEM-T-ech42 - this gives a single band of 1,934 bp in the wild type and two bands of 1,682 and 8,126 bp in the disrupted mutants (a single $\mathrm{XbaI}$ site is present in pAN7-1 on $\operatorname{trpC}, 64 \mathrm{bp}$ from the HindIII site) - if the expected homologous insertion occurred at the ech42 locus (Fig. 1); (iii) ability of the mutants to grow and sporulate similarly to the wild type on PDA with or without HygB; and (iv) lack of the ability to clear a chitincontaining medium, compared with strain P1. These chitin assays were performed by growing fungal agar plugs (from 3day-old cultures on PDA or PDA+HygB) on SM agar plates containing $0.1 \%(\mathrm{wt} / \mathrm{vol})$ sucrose, $3 \%$ (wt/vol) colloidal chitin, and $0.1 \%$ (vol/vol) Igepal (to slow down colony growth; Sigma Chemical, Milan). Evaluation of the cleared zones around the growing cultures was conducted for 4 to 14 days. Strain development was determined by measuring the rate of growth and spore counts of cultures grown on plates of PDA or bean seed filtrate media solidified with agar $1 \%$ (wt/vol).

\section{Molecular characterization of mutants.}

Fungal DNA was extracted from frozen biomass following the procedure of Raeder and Broda (1985). PCR amplification was performed with $20 \mathrm{ng}$ of DNA by previously described procedures (Woo et al. 1996): one cycle of $3 \mathrm{~min}$ at $94^{\circ} \mathrm{C}$ and $1 \mathrm{~min}$ at $55^{\circ} \mathrm{C}$, followed by 34 cycles of $1 \mathrm{~min}$ at $94^{\circ} \mathrm{C}, 1 \mathrm{~min}$ at $55^{\circ} \mathrm{C}$, and $3 \mathrm{~min}$ at $72^{\circ} \mathrm{C}$, and a final cycle of $1 \mathrm{~min}$ at $94^{\circ} \mathrm{C}, 1 \mathrm{~min}$ at $55^{\circ} \mathrm{C}$, and $7 \mathrm{~min}$ at $72^{\circ} \mathrm{C}$. A 574-bp portion of ech 42 including the $3^{\prime}$ end was amplified with the primers E8F and End, which anneal at +898 and +1472 close to the stop codon of the gene, respectively (Fig. 1; Table 1). A 808-bp portion at the $5^{\prime}$ end of ech42 was amplified with the primers NCO, which anneals at +5 , and B1N (+813; Fig. 1; Table 1). Nearly the entire coding sequence (1,467 bp) was amplified with NCO and End (Fig. 1), while the primers NCO within ech42 and $\mathrm{TrF}$ within the hygromycin resistance cassette were used to amplify a 1,892-bp band to confirm homologous insertion (Fig. 1). The RNA for Northern analysis was obtained from colonies growing in the presence of colloidal chitin as the sole carbon source or $B$. cinerea purified cell walls (Garcia et al. 1994; Hayes et al 1994; Lorito et al. 1996b). Northern blots and RNA extraction were performed by standard protocols (Sambrook et al. 1989); $10 \mu \mathrm{g}$ of RNA and the entire ech 42 coding region were used as a DNA probe. Southern blot analysis of selected mutants was performed with either radioactive or nonradioactive probes by standard methods (Sambrook et al. 1989; Boehringer Mannheim, Indianapolis, IN) on $5 \mu \mathrm{g}$ of genomic DNA digested with HindIII $(-196$ and +1333 on ech42), EcoRI ( -360 on ech42 and two restriction sites on pAN7-1), or EcoRV, which has no cleavage sites on either ech42 or pAN7-1 (Hayes et al. 1994; Punt et al. 1987), hybridized at 62 to $65^{\circ} \mathrm{C}$.

Southerns and Northerns of nagl (encoding the main $\mathrm{N}$ acetyl- $\beta$-D-glucosaminidase secreted by strain P1-CHIT72) (Lorito et al. 1994a, 1998; Peterbauer et al. 1996) were performed as indicated above with the entire coding sequence of this gene as a probe, to determine if the disruption of ech 42 had an affect on nagl expression. PCR analysis of nagl used primers $95 \mathrm{~F}+1480 \mathrm{R}$ and $535 \mathrm{~F}+1989 \mathrm{R}$ to amplify the two ends, and $535 \mathrm{~F}+1480 \mathrm{R}$ and $95 \mathrm{~F}+1989 \mathrm{R}$ to amplify the internal portion or the entire sequence, respectively (Table 1).

\section{Enzyme assays.}

Culture filtrates obtained from fungi grown under inducing conditions (see above) were centrifuged at 5,000 rpm (centrifuge; Beckman, Fullerton, CA) for $25 \mathrm{~min}$. The supernatant was filtered through a $0.22-\mu \mathrm{m}$ filter, concentrated about 40 -fold by dialysis (7,000 to 8,000 cutoff) with polyethylene glycol (7-8000 MW; Fluka Chemika-Biochemika, Buchs, Switzerland), dialyzed against distilled water for $16 \mathrm{~h}$ at $4^{\circ} \mathrm{C}$, dialyzed with two changes of a $50 \mathrm{mM}$ potassium phosphate buffer $\left(\mathrm{KPO}_{4}, \mathrm{pH}\right.$ 6.8) over $48 \mathrm{~h}$ at $4^{\circ} \mathrm{C}$, syringe filtered through a $0.45-\mu \mathrm{m}$ filter, and then stored at $4^{\circ} \mathrm{C}$ until use or lyophilized and stored at $-20^{\circ} \mathrm{C}$. The filtrates were subjected to native PAGE followed by Coomassie staining, or unstained gels were overlaid with a solution of the fluorescent substrates $(300 \mu \mathrm{g} / \mathrm{ml})$ 4-methylumbelliferyl- $\beta$-D- $N, N^{\prime}, N^{\prime \prime}$-triacetylchitotrioside (Sigma Chemical, Milan) and 4-methylumbelliferyl- $N$-acetyl- $\beta$-D-glucosaminide (Sigma Chemical), which detect endochitinase (EC 3.2.1.14) and $N$-acetyl- $\beta$-D-glucosaminidase activity (NAGase) ( $\beta-N$ acetylhexosaminidase, EC 3.2.1.52), respectively (Webb 1992; Tronsmo and Harman 1993). After the overlay, gels were kept at 
$30^{\circ} \mathrm{C}$ and the appearance of the enzyme bands was constantly monitored for up to $30 \mathrm{~min}$. The presence or the absence of CHIT42 was also determined by ELISAs with antibodies prepared against the purified endochitinase from T. harzianum P1, and by measuring the reduction in turbidity of colloidal chitin suspensions after a 24-h incubation (Harman et al. 1993). Other enzyme activities in the culture filtrates were assayed as previously described (Harman et al. 1993; Lorito et al. 1994a): total chitinolytic activity on chitin (reducing sugars assay), $\mathrm{N}$-acetyl$\beta$-D-glucosaminidase (NAGase) on $p$-nitrophenyl $N$-acetyl- $\beta$-Dglucosaminide (Sigma) (colorimetric assay), chitin 1,4- $\beta$-chitobiosidase (chitobiosidase) on $p$-nitrophenyl $\beta$-D- $N, N^{\prime}$-diacetylchitobiose (Sigma), exo-glucanase on $p$-nitrophenyl $\beta$-Dglucopyranoside (Sigma), and glucan 1,3- $\beta$-glucosidase (EC 3.2.1.58; Webb 1992) on laminarin (reducing sugar assay). Protein concentration in the enzyme preparations was determined by the Micro BCA protein assay (Pierce, Rockford, IL) with trypsin inhibitor from soybean (Sigma) as the standard protein.

All the experiments were performed with samples from strain P1 as the wild-type control and were conducted at least twice. Values from the enzyme assays, containing at least three replicates per sample, were averaged and standard deviations were determined. The terminology used in this paper to distinguish the various chitinolytic enzyme activities is the same as reported by Harman et al. (1993)

\section{Biocontrol assays.}

In vitro biocontrol assays against $B$. cinerea were performed with the mutant and wild-type culture filtrates in ELISA plates with an inverted microscope (Lorito et al. 1996c). All the bioassays included controls containing sterile water and the antifungal effect was quantified by determining the inhibition of spore germination or hyphal elongation (Lorito et al. 1994a). To study the effect caused by the absence of the endochitinase on the antifungal activity of the culture filtrates, purified endochitinase CHIT42 from strain P1 (Harman et al. 1993) was also added at concentrations ranging from 1 to $15 \mu \mathrm{g} / \mathrm{ml}$ to the mutant culture filtrate. In vitro biocontrol assays against $R$. solani were performed by placing a PDA disk $(0.5 \mathrm{~mm})$ of a 10-day-old fungal culture in a layer of $1 \%$ water agar (WA, $600 \mu \mathrm{l}$ ) thinly spread on a sterile microscope slide. After incubation for 1 day at $25^{\circ} \mathrm{C}$ and $100 \%$ relative humidity, $200 \mu \mathrm{l}$ of the various culture filtrates, dissolved in sodium citrate buffer $(50 \mathrm{mM} \mathrm{pH} 4.8)$, was spread on the WA surface and the slides were incubated at $25^{\circ} \mathrm{C}$ and $100 \%$ relative humidity. Mycelial inhibition was determined by measuring the colony growth microscopically from 1 to $7 \mathrm{~h}$ after filtrate application. Confrontation assays were conducted on plates containing PDA with $0.1 \%$ (vol/vol) Igepal (SigmaAldrich), or SM with agar and $0.1 \%$ (wt/vol) sucrose.

In vivo biocontrol tests on leaves were performed with mutant and wild-type strains against $B$. cinerea on bean plants (Phaseolus vulgaris cv. Cannellini). Final spore concentrations used were $10^{6}$ spores per $\mathrm{ml}$ for T. harzianum and $10^{5}$ spores per $\mathrm{ml}$ for $B$. cinerea, in a buffer containing $20 \mathrm{mM}$ glucose and $20 \mathrm{mM}$ potassium phosphate $\left(\mathrm{KH}_{2} \mathrm{PO}_{4}\right)$, with a total inoculation volume of $20 \mu \mathrm{l}$. Two inoculation points were performed on each of a minimum of three leaves per plant; each treatment contained 30 plants and two replicates were performed in each experiment. Plants were misted frequently and maintained at $25^{\circ} \mathrm{C}$ with light. Evaluations were conducted every 2 days, up to 1 month after inoculation.
Various biocontrol tests in vivo were conducted with different soilborne plant pathogens. Bean seeds were coated with a $10 \%$ (wt/vol) aqueous suspension of an adhesive (Pelgel; Liphatech, Milwaukee, WI) containing $10^{9}$ spores per $\mathrm{ml}$ of the different $T$. harzianum strains $(1 \mathrm{ml}$ of spore suspension per $15 \mathrm{~g}$ of seed) and left to air dry. Humid pathogen-infested soil was prepared as follows: for P. ultimum, two parts of infected field soil were mixed with one part of sterilized soil; and for $R$. solani, $3 \mathrm{~g}$ of fresh fungal biomass homogenized in distilled water was mixed with 1 liter of sterile soil. Treated bean seeds were planted $4 \mathrm{~cm}$ deep in the infested soil and maintained at $25^{\circ} \mathrm{C}$ with light, and kept moist. The number of plants emerging or surviving and the plant height were evaluated twice weekly for up to 1 month after planting.

For all in vivo biocontrol assays, infected plant material was plated onto acidified PDA to verify the presence of the test fungi, and all pathogens were re-isolated from infected plants to maintain virulence. All in vitro and in vivo biocontrol assays contained three or more treatment replicates per experiment and the experiments were conducted two or more times on separate occasions. The results presented are the average values obtained from all the experiments. Percent survivability was calculated as the percentage of plants that emerged divided by the number of seeds planted. Statistical analyses included a one-way analysis of variance (ANOVA) on arcsine transformed percent values or raw data obtained from measured enzyme activities, fungal colony growth, or plant height, with a significance level at $P<0.05$. Due to poor emergence and deformed growth of control plants (seed treated with Pelgel or water) in the assays with pathogeninfested soil, it was not possible to include these data in the ANOVA. Therefore, unpaired $t$ tests were conducted between the wild-type and mutant strains to determine differences.

\section{ACKNOWLEDGMENTS}

We are grateful to the following: Rosalia Ciliento, Kathi Payer, and Paola Sposato for their help in constructing and testing the mutants; Antonio Romeo for assisting with the bioassays; Kristen Ondik for revisions to the manuscript; Peter Punt for providing the plasmid p-AN7-1; and Jyothi P. Bolar for providing the nagl primers. S. L. W. was partially supported by research fellowships from CRAA (Consorzio per la Ricerca Applicata in Agricoltura) and Cornell University. M. L. acknowledges a grant from the Fullbright Program. The research was supported in part with grants from NATO (CRG 931173), the "Protocollo di Cooperazione Scientifica Italia-Austria" financed by MURST, and the EC grant FAIR-4140; and, in the U.S., by a grant from the US-Israel Binational Agriculture Research Development (BARD) fund.

\section{LITERATURE CITED}

Belanger, R. R., Dufour, N., Caron, J., and Benhamou, N. 1995. Chronological events associated with the antagonistic properties of Trichoderma harzianum against Botrytis cinerea: Indirect evidence for sequential role of antibiosis and parasitism. Biocontrol Sci. Technol. 5:41-53.

Benhamou, N., Rey, P., Chérif, M., Hockenhull, J., and Tirilly, Y. 1997. Treatment with the mycoparasite Pythium oligandrum triggers induction of defense-related reactions in tomato roots when challenged with Fusarium oxysporum f. sp. radicis-lycopersici. Phytopathology 87:108-122.

Caron, J. 1993. Isolement et caractérisation de divers isolats de Trichoderma comme agent de lutte biologique contre la moisissure grise (Botrytis cinerea) dans la production de la fraise. M.S. thesis, no. 12350. Université Laval, Québec.

Carsolio, C., Gutiérrez, A., Jiménez, B., van Montagu, M., and HerreraEstrella, A. 1994. Characterization of ech-42, a Trichoderma harzianum endochitinase gene expressed during mycoparasitism. Proc. Natl. 
Acad. Sci. USA 91:10903-10907.

Chet, I. 1987. Trichoderma - Application, mode of action, and potential as a biocontrol agent of soilborne plant pathogenic fungi. Pages 137160 in: Innovative Approaches to Plant Disease Control. I. Chetl, ed. J. Wiley and Sons, New York.

Chet, I., Barak, Z., and Oppenheim, A. 1993. Genetic engineering of microorganisms for improved biocontrol activity. Pages 211-255 in: Biotechnology in Plant Disease Control. I. Chet, ed. Wiley-Liss, New York.

de la Cruz, J., Hidalgo-Gallego, A., Lora, J. M., Benitez, T., Pintor-Toro, J. A., and Llobell, A. 1992. Isolation and characterization of three chitinases from Trichoderma harzianum. Eur. J. Biochem. 206:859-867.

Di Pietro, A., Lorito, M., Hayes, C. K., Broadway, R. M., and Harman, G. E. 1993. Endochitinase from Gliocladium virens: Isolation, characterization, and synergistic antifungal activity in combination with gliotoxin. Phytopathology 83:308-313.

Galhaup, C., Zeilinger, S., Woo, S. L., Mach, R. L., Lorito, M., and Kubicek, C. P. 1998. Use of the green fluorescent protein as a reporter system reveals Trichoderma harzianum ech 42 gene expression as a very early, precontact event of mycoparasitic interaction. Page 249 in: Fungal Genetics, Abstract Book of the Fourth European Conference on Fungal Genetics. Universidad de Leon, Leon, Spain.

Garcia, I., Lora, J. M., de la Cruz, J., Benitez, T., Llobell, A., and PintorToro, J. A. 1994. Cloning and characterization of a chitinase (CHIT42) cDNA from the mycoparasitic fungus Trichoderma harzianum. Curr. Genet. 27:83-89.

Haran, S., Schickler, H., Oppenheim, A., and Chet, I. 1994. New components of the chitinolytic system of Trichoderma harzianum. Mycol. Res. 99:441-446.

Haran, S., Schickler, H., Oppenheim, A., and Chet, I. 1996. Differential expression of Trichoderma harzianum chitinases during mycoparasitism. Phytopathology 86:980-985.

Harman, G. E., and Hayes, C. K. 1996. Biologically-based technologies for pest control: Pathogens and pests of agriculture. Report to the Office of Technology Assessment, US Congress, April 1996.

Harman, G. E., Hayes, C. K., Lorito, M., Broadway, R. M., Di Pietro, A., Peterbauer, C., and Tronsmo, A. 1993. Chitinolytic enzymes of Trichoderma harzianum: Purification of chitobiosidase and endochitinase. Phytopathology 83:313-318.

Harman, G. E., and Kubicek, C. P. 1998. Trichoderma and Gliocladium. Vol. 2. Taylor \& Francis, London.

Hayes, C. K., Klemsdal, S., Lorito, M., Di Pietro, A., Peterbauer, C., Nakas, J. P., Tronsmo, A., and Harman, G. E. 1994. Isolation and sequence of an endochitinase-encoding gene from a cDNA library of Trichoderma harzianum. Gene 138:143-148.

Howell, C. R. 1987. Relevance of mycoparasitism in the biological control of Rhizoctonia solani by Gliocladium virens. Phytopathology 77: 992-994.

Inbar, J., and Chet, I. 1995. The role of recognition in the induction of specific chitinases during mycoparasitism of Trichoderma harzianum. Microbiology 141:2823-2829.

Kubicek, C. P., and Harman, G. E. 1998. Trichoderma and Gliocladium. Vol. 1. Taylor \& Francis, London.

Limón, M. C., Llobell, A., Pintor-Toro, J. A., and Benitez, T. 1996. Overexpression of chitinase by Trichoderma harzianum strains used as biocontrol fungi. Pages 245-252 in: Chitin Enzymology II. R. A. A. Muzzarelli, ed. Atec Edizioni, Grottammare (AP), Italy.

Limón, M. C., Lora, J. M., Garcia, I., de la Cruz, J., Llobell, A., Benitez, T., and Pintor-Toro, J. A. 1995. Primary structure and expression pattern of the 33-kDa chitinase gene from the mycoparasitic fungus Trichoderma harzianum. Curr. Genet. 28:478-483.

Lorito, M. 1998. Chitinolytic enzymes and their genes. Pages 73-99 in: Trichoderma and Gliocladium. Vol. 2. G. E. Harman and C. P. Kubicek, eds. Taylor \& Francis, London.

Lorito, M., Di Pietro, A., Hayes, C. K., Woo, S. L., and Harman, G. E. 1993a. Antifungal, synergistic interaction between chitinolytic enzymes from Trichoderma harzianum and Enterobacter cloacae. Phytopathology 83:721-728.

Lorito, M., Farkas, V., Rebuffat, S., Bodo, B., and Kubicek, C. P. 1996a. Cell-wall synthesis is a major target of mycoparasitic antagonism by Trichoderma harzianum. J. Bacteriol. 178:6382-6385.

Lorito, M., Harman, G. E., Hayes, C. K., Broadway, R. M., Tronsmo, A., Woo, S. L., and Di Pietro, A. 1993b. Chitinolytic enzymes produced by Trichoderma harzianum: Antifungal activity of purified endochitinase and chitobiosidase. Phytopathology 83:302-307.
Lorito, M., Hayes, C. K., Di Pietro, A., and Harman, G. E. 1993c. Biolistic transformation of Trichoderma harzianum and Gliocladium virens using plasmid and genomic DNA. Curr. Genet. 24:349-356.

Lorito, M., Hayes, C. K., Di Pietro, A., Woo, S. L., and Harman, G. E. 1994a. Purification, characterization and synergistic activity of a glucan $1,3-\beta$-glucosidase and an $N$-acetyl- $\beta$-glucosaminidase from Trichoderma harzianum. Phytopathology 84:398-405.

Lorito, M., Peterbauer, C., Hayes, C. K., and Harman, G. E. 1994b. Synergistic interaction between fungal cell wall-degrading enzymes and different antifungal compounds enhances inhibition of spore germination. Microbiology 140:623-629.

Lorito, M., Peterbauer, C., Sposato, P., Mach, R. L., Strauss, J., and Kubicek, C. P. 1996b. Mycoparasitic interaction relieves binding of the Cre1 carbon catabolite repressor protein to promoter sequences of the ech-42 (endochitinase-encoding) gene in Trichoderma harzianum. Proc. Natl. Acad. Sci. USA 93:14868-14872.

Lorito, M., Woo, S. L., D’Ambrosio, M., Harman, G. E., Hayes, C. K., Kubicek, C. P., and Scala, F. 1996c. Synergistic interaction between cell wall degrading enzymes and membrane affecting compounds. Mol. Plant-Microbe Interact. 9:206-213.

Lorito, M., Woo, S. L., Garcia Fernandez, I., Colucci, G., Harman, G. E., Pintor-Toro, J. A., Filippone, E., Muccifora, S., Lawrence, C. B., Zoina, A., Tuzun, S., and Scala, F. 1998. Genes from mycoparasitic fungi as a source for improving plant resistance to fungal pathogens. Proc. Natl. Acad. Sci. USA 95:7860-7865.

Lumsden, R. D., and Lewis, J. A. 1989. Selection, production, formulation and commercial use of plant disease biocontrol fungi: Problems and progress. Pages 171-190 in: Biotechnology of Fungi for Improving Plant Growth. J. M. Whipps and R. D. Lumsden, eds. Cambridge University Press, Cambridge.

Melo, I. S., Faull, J. L., and Graeme-Cook, K. A. 1997. Relationship between in vitro cellulase production of UV-induced mutants of Trichoderma harzianum and their bean rhizosphere competence. Mycol. Res. 101:1389-1392.

Peterbauer, C., Lorito, M., Hayes, C. K., Harman, G. E., and Kubicek, C. P. 1996. Molecular cloning and expression of nagl ( $N$-acetyl- $\beta$-Dglucosaminidase-encoding) gene from Trichoderma harzianum P1. Curr. Genet. 29:812-820.

Prokkola, S. 1992. Antagonistic properties of Trichoderma species against Mycocentrospora acerina. Pages 76-79 in: New Approaches in Biological Control of Soil-borne Diseases. IOBC:WPRS Bull. D. F. Jensen, J. Hockenhull, and N. Fokkema, eds. IOBC/WPRS, Dijon, France.

Punt, P. J., Oliver, R., Dingemanse, M. A., Pouwels, P. H., and van den Hondel, C. A. M. J. J. 1987. Transformation of Aspergillus based on the hygromycin B resistance marker from Escherichia coli. Gene 56: 117-124.

Raeder, U., and Broda, P. 1985. Rapid preparation of DNA from filamentous fungi. Lett. Appl. Microbiol. 1:17-20.

Sambrook, J., Fritsch, E. F., and Maniatis, T. A. 1989. Molecular Cloning: A Laboratory Manual. 2nd ed. Cold Spring Harbor Laboratory, Cold Spring Harbor, NY.

Schirmböck, M., Lorito, M., Wang, Y. L., Arisan-Atac, I., Scala, F., and Kubicek, C. P. 1994. Parallel formation and synergism of hydrolytic enzymes and peptaibol antibiotics, molecular mechanisms involved in the antagonistic action of Trichoderma harzianum against phytopathogenic fungi. Appl. Environ. Microbiol. 60:9-16.

Tronsmo, A. 1991. Biological and integrated controls of Botrytis cinerea on apple with Trichoderma harzianum. Biological Control 1:59-62.

Tronsmo, A., and Harman, G. E. 1993. Detection and quantitation of $N$ acetyl- $\beta$-D-glucosaminidase, chitobiosidase and endochitinase in solution and on gels. Anal. Biochem. 208:74-79.

Ulhoa, C. J., and Peberdy, J. F. 1991. Purification and characterization of an extracellular chitobiase from Trichoderma harzianum. Curr. Microbiol. 23:285-289.

Ulhoa, C. J., and Peberdy, J. F. 1992. Purification and some properties of the extracellular chitinase produced by Trichoderma harzianum. Enzyme Microb. Technol. 14:236-240.

Webb, C. 1992. Enzyme Nomenclature. Academic Press, San Diego, CA.

Whipps, J. M. 1997. Development in the biological control of soil-borne plant pathogens. Adv. Bot. Res. 26:1-134.

Woo, S. L., Zoina, A., Del Sorbo, G., Lorito, M., Nanni, B., Scala, F., and Noviello, C. 1996. Characterization of Fusarium oxysporum f. sp. phaseoli by pathogenic races, VCGs, RFLPs, and RAPD. Phytopathology 86:966-973. 